\title{
FAXINANDO COM A VODUNSI ${ }^{1}$
}

\author{
Guilherme Dantas Nogueira²
}

\begin{abstract}
Resumo: Objetivo com este artigo mostrar que a autoridade de uma mulher candomblecista é construída a partir de uma lógica vivencial, em que posições hierarquicamente mais elevadas são alcançadas a partir de seu tempo de iniciação e da partilha em papeis comunitários e religiosos variados, pelos quais todas devem passar. Isso é parte do longo caminho iniciático candomblecista, que envolve, dentre outros diversos elementos, solidariedade, abraços, rezas e faxinas. Este caminho é debatido no texto e reflexões são apresentadas em caráter decolonial. Como ponto central do debate, narro uma experiência de faxina que vivenciei com uma mãe candomblecista angoleira velha de santo. Alguns elementos e sentimentos presentes nesta interação são apresentados e analisados. $O$ grande respeito e a autoridade que aquela mãe me suscitava, aliado a meu lugar de fala como ogan, deram o tom da interação. O caráter feminino, subversivo e nada ascético do Candomblé complementa o conjunto de observações e considerações tecidas no texto.
\end{abstract}

Palavras-chave: Candomblé; mãe candomblecista; ogan; gênero; faxina.

\section{Introdução}

Este texto nasce de uma experiência e de um constrangimento que experimentei em janeiro de 2017, durante uma mudança de casa. Como parte do trabalho de esvaziar o apartamento em que morava e levar minhas coisas para a casa nova, precisei contratar um trabalho profissional de limpeza. Para tanto, aceitei a recomendação de uma faxineira indicada por uma amiga, a vodunsi Dandinha, religiosa de cargo alto em um terreiro de Candomblé de Brasília/DF. Para a minha surpresa, a faxineira indicada era uma candomblecista de autoridade ainda maior, àquele momento com 46 anos de santo ${ }^{3}$, chamada mãe Sinhá.

A interação daquele dia de faxina, aliada ao meu sentimento de profundo respeito por aquela senhora, motivaram-me a escrever este artigo. Proponho aqui, assim,

\footnotetext{
$1 \mathrm{O}$ presente trabalho foi realizado com apoio do CNPq, Conselho Nacional de Desenvolvimento Científico e Tecnológico - Brasil. Texto versa sobre questões em pesquisa pelo autor como parte de sua tese de doutorado.

${ }^{2}$ Doutorando em Sociologia, pela Universidade de Brasília, orientado pela professora doutora Tânia Mara Campos de Almeida. Integrante do Calundu - Grupo de Estudos sobre Religiões Afro-Brasileiras. guidantasnog@gmail.com.

3 A expressão "anos de santo" se refere ao tempo como iniciada que uma pessoa tem no Candomblé. Conforme antiga expressão angoleira, no Candomblé, "antiguidade é posto". Ou seja, quanto mais velha de santo for uma pessoa, mas distinta será.
} 
narrar e refletir sociologicamente sobre a experiência da faxina com mãe Sinhá. Objetivo mostrar que a autoridade de uma candomblecista é construída a partir de uma lógica vivencial, em que posições hierarquicamente mais elevadas são alcançadas a partir de seu tempo de iniciação e da partilha em papeis comunitários e religiosos variados, pelos quais todas devem passar. Este caminhar junto ao grupo traz senioridade e respeito, mesmo para religiosas que, para fora dos muros dos terreiros, sejam marginalizadas socialmente e jamais possam alcançar posições de autoridade na lógica e hierarquia social da colonial modernidade brasileira.

Dividi o texto em dois itens principais: no primeiro, apresento uma exposição sócio-antropológica sobre o papel e a importância das mulheres no Candomblé, e seu contraste com a posição social dessas mesmas na colonial modernidade brasileira. Esta exposição é o marco teórico que me auxilia a situar as reflexões que busco fazer. No segundo item, narro a experiência da faxina indicada e apresento as reflexões que o episódio me suscitou.

Para seguir com o debate, faz-se necessário que, antes de mais nada, seja exposto meu lugar de fala, que é o de um pesquisador da Sociologia e, ao mesmo tempo, de um candomblecista iniciado na nação religiosa Angola, especificamente na tradição conhecida como Moxicongo, nascida com a fundação do terreiro do Bate Folha, em Salvador/BA. Por ser meu relato uma interação vivida por mim e por mãe Sinhá, minha filiação religiosa é determinante para os resultados deste artigo.

Como candomblecista, sou ogan, papel e cargo religioso diferente daquele mais comumente conhecido como rodante. Ogans são os candomblecistas responsáveis dentre outras variadas e complexas atividades internas e externas - pela condução da orquestra dos terreiros. Devem, além disso, vivenciar todos os rituais com os olhos abertos, ou seja, sem entrar em transe religioso. Rodantes, por sua vez, como mãe Sinhá, são as/os candomblecistas que entram em transe e incorporam inquices ${ }^{4}$.

No Candomblé do Bate Folha e em suas "casas filhas" - como a minha própria, que é uma "casa neta" - rodantes são também chamados de vodunsis - termo apropriado do culto aos voduns, da nação religiosa Jeje e suas tradições. Esta apropriação terminológica carrega um contexto de época: o Candomblé do Bate Folha foi oficialmente inaugurado no ano de 1916, época em que religiosos soteropolitanos, a exemplo do que também ocorria em séculos anteriores, vivenciavam a religiosidade de

\footnotetext{
${ }^{4}$ No Candomblé, inquices são as divindades cultuadas pela nação religiosa Angola, a exemplo dos orixás, cultuados pela nação Ketu, e voduns, cultuados pela nação Jeje.
} 
seus terreiros e se esforçavam por tomar parte na vida religiosa de outras comunidades candomblecistas. Este comportamento dinamizava uma rede de solidariedade, em que informações, bens físicos e conhecimentos religiosos eram trocados entre adeptos e fortaleciam as diferentes comunidades e o povo negro como um todo (SILVEIRA, 2006; SANTOS, 2009).

Embora menos visível e menor, as redes de solidariedade entre religiosos e suas comunidades de terreiro ainda existem. Foi devido a elas que optei por contratar uma faxineira indicada por uma candomblecista. Ainda que não soubesse que mãe Sinhá era "do santo", sabia que, seguindo a indicação, trabalharia com uma pessoa relacionada/próxima ao terreiro da vodunsi Dandinha.

Por cuidado com as personagens reais aqui citadas, utilizei neste trabalho pseudônimos, que foram escolhidos por dizerem algo sobre as pessoas reais: Dandinha (e Danda, que virá logo abaixo) se remete a Dandalunda, ou Dangualunda, divindade da cachoeira para o Candomblé Angola, também conhecida no Brasil pelo nome Oxum (que é a divindade com a qual Dandalunda se sincretiza nos Candomblés que usam como língua ritual o iorubá), que acompanha a vodunsi Dandinha. E Sinhá se refere à senhora da casa grande colonial, a quem todos deviam respeito - que, na experiência que narro é muito mais devido à mãe Sinhá. A princípio não haveria problemas em citar os nomes reais, mesmo porque nada de calamitoso é aqui exposto. Pseudônimos, não obstante, evitam outras situações de constrangimento e não interferem no desenrolar do texto. Suprimi também da versão aqui narrada da história da minha interação com mãe Sinhá algumas passagens secundárias e personagens terceiras, que não alteram meus argumentos, mas são dispensáveis - e se tornariam morosas - para o contar dos fatos. A história da faxina está, portanto, resumida, mas não por isso menos rica.

\section{As vodunsis e o trabalho doméstico}

Similarmente ao fato de que ogans são exclusivamente homens, vodunsis candomblecistas $^{5}$ eram até a primeira metade do século XX quase exclusivamente mulheres (LANDES, 1947/1994). Com efeito, em alguns terreiros da nação religiosa Ketu, como a "casa mãe” Ilê Axé Iyá Nassô Oká, ainda no presente apenas mulheres

\footnotetext{
${ }^{5}$ Pode parecer um pleonasmo falar "vodunsis candomblecistas", mas ogans e rodantes não são uma exclusividade do Candomblé. Pelo contrário, embora as denominações, gêneros, e detalhes dos papeis possam variar, em todas as religiões afro-brasileiras é possível encontrar religiosos/as responsáveis pela orquestra dos terreiros - que geralmente mantém seus olhos abertos - e outros/as que entram em transe.
} 
podem ser iniciadas como rodantes, consequentemente a líder religiosa será sempre uma mulher. No Bate Folha, por sua vez, homens podem ser vodunsis, mas em geral e em grande maioria serão as mulheres que serão iniciadas para este papel. Em um universo em que papeis religiosos (e não sociais e de forma alguma preferências sexuais) ditam as regras do sistema, o sexo biológico é central para que os mesmos sejam distribuídos entre pessoas (SEGATO, 1986/2005).

Esta prática de se iniciar mormente mulheres como rodantes se confunde com o contexto da fundação do Candomblé na Bahia. E, antes deste, com a forma como historicamente foram construídas, ao longo de três séculos, as estruturas dos Calundus coloniais - primeiro construto afro-ameríndio-religioso no Brasil, que serviu como base para todas as denominações afrorreligiosas hodiernas.

Comunidades candomblecistas foram, historicamente, e permanecem no presente estruturadas sob a lógica do espaço doméstico. Ao passo que mulheres (sempre se tratando de sexo biológico) e homens podem ser empossados como mães ou pais de santo, ou seja, como os líderes máximos, a comunidade religiosa será estruturada exclusivamente sob o domínio do feminino, da organização doméstica do trabalho e da família de santo (BIRMAN, 1995; SILVA, 2013; NOGUEIRA, 2016). Considerando isso, a antropóloga Patrícia Birman (1995) indica ser possível que Candomblés sejam fundados e funcionem perfeitamente sem homens, com todas as atividades internas sendo executadas por mulheres. Para aquelas tarefas em que é indispensável a presença dos ogans, os mesmos podem ser contratados de outras comunidades e remunerados, voltando às suas casas de origem após executarem-nas. O contrário, todavia, não é possível e nem imaginável - não há terreiros de Candomblé sem mulheres (BIRMAN, 1995).

A exposição de Birman (1995) traz implícita a assumpção da autora - e antes dela da antropóloga Ruth Landes (1947/1994) e do sociólogo Edison Carneiro (1961) de que o sentido de existir das comunidades candomblecistas é o transe afrorreligioso. Não partilho desta visão e defendo, junto à educadora Denise Botelho e ao filósofo Wanderson Nascimento (2010), que a motivação de existência destas comunidades é a perpetuação e reprodução de suas tradições e modo de vida afro-comunitário-religioso. Ainda assim, Birman (1995) nos ajuda a dimensionar a importância das vodunsis - e das mulheres candomblecistas como um todo - em oposição aos homens, sejam ogans ou rodantes. Esses - e particularmente os ogans - são indispensáveis para a contínua existência do Candomblé. Mas não possuem papel estruturador nas comunidades 
religiosas, razão pela qual podem ser tratados e remunerados como ajudantes externos.

São como pilares de suas comunidades de terreiro que as vodunsis - e junto a elas as makotas (mulheres que não entram em transe e possuem como principal papel religioso, "com os olhos abertos", a assistência aos inquices em suas necessidades) devem ser vistas. Efetivamente, o minucioso, estratégico e contra-hegemônico trabalho de preservação e reprodução de seus cultos e de estruturação de suas comunidades vem sendo empreendido por religiosas, em colaboração umas com as outras em ampla resistência aos intentos violentos da Colônia, Império e Estado brasileiro - e valendo-se de conhecimentos e habilidades acumulados tanto na África quanto no Brasil - desde os tempos da escravidão (SEGATO, 1986/2005). Foi devido a esta ação político-social empreendida por essas mulheres e liderada pelas mães de santo que a afrorreligiosidade se preservou no Brasil (SCHUMAHER e BRAZIL, 2013).

Dentro dessa estrutura, o trabalho doméstico ${ }^{6}$ se torna parte integrante do processo iniciático de rodantes e makotas no Candomblé. Desde os primeiros momentos em que estas/es religiosas/os aderem aos terreiros (alguns/mas na infância) e dão seus primeiros passos iniciáticos, entram em um longo caminho de participação em faxinas, cozinhas, arrumações, etc., necessárias para o funcionamento das casas religiosas e que, combinadas com atividades religiosas específicas, devem ser divididas entre todas/os. Há aqui uma pedagogia própria, construída a partir de heranças africanas que são reproduzidas e repassadas em terreiros, em que todas/os tomam parte e que possibilitam a reprodução do modo de vida afrorreligioso brasileiro (BOTELHO e NASCIMENTO, 2010) e que não encontra paralelo na colonial modernidade.

Birman (1995) - a partir de ampla pesquisa de campo - observa que esta lógica será mais marcante para as atividades não religiosas das mulheres, posto que os homens vodunsis, tal como os ogans, terminarão por receber com mais frequência trabalhos externos ao terreiro, como ir às compras. E - sempre se tratando de atividades não religiosas - executarão, igualmente, trabalhos não domésticos, como eventuais serviços de pintura ou manutenção/reformas dos terreiros. Para a autora, a lógica da divisão do trabalho não religioso favorece que, seguindo a socialmente estabelecida divisão de espaços domésticos e públicos, mulheres se especializem nas atividades domésticas e

\footnotetext{
${ }^{6} \mathrm{O}$ trabalho doméstico pode ser dividido em dois grupos: trabalho feito com rezas - envolve todo o trabalho realizado nos terreiros que depende de conhecimento ritual, como cozinhar para o santo ou faxinas espirituais; e trabalho feito sem rezas - envolve todo o trabalho que pode ser realizado sem conhecimento ritual prévio. Ambos os grupos são importantes e sagrados, pois, para a cosmopercepção afrorreligiosa, tudo é sagrado (o profano não existe).
} 
homens nas outras.

Esta exposição de Birman (1995) sobre a divisão gendrada do trabalho não religioso nas comunidades candomblecistas reitera e sustenta o argumento que venho buscando defender: a realização de variados trabalhos domésticos é parte do caminho iniciático de makotas e mulheres vodunsis no Candomblé. A senioridade nesta religião é, portanto, alcançada com idade de santo e também com a colaboração na divisão dos trabalhos, necessária para a manutenção da casa e da comunidade religiosa.

Dentre todos os trabalhos domésticos, destaco neste texto a faxina. No próximo item, dedico-me a descrever a experiência da faxina que vivenciei com mãe Sinhá e a tecer reflexões sobre a mesma. Por se tratar de uma experiência que coloca em cena para valer-me aqui, por empréstimo, de expressões da metáfora do teatro - uma vodunsi e um ogan, e sustentado pela observação de Birman (1995) de que o caminho iniciático de uma mulher rodante será, pelos trabalhos realizados, diferente ao de um homem rodante, passarei a referir-me sempre a vodunsis no feminino. São as experiências, finalmente, da vodunsi mãe Sinhá e a minha própria que interagem na experiência empírica aqui narrada. Papeis religiosos constroem o palco do drama, mas o gênero faz parte dos bastidores deste enredo.

\section{A faxina}

A faxina com mãe Sinhá começou logo pela manhã. O apartamento em questão já estava vago e fui encontrá-la na porta - a vodunsi Dandinha a dirigiu até meu endereço - para, juntos, fazermos a limpeza. Foi neste momento, inclusive, que mãe Sinhá me foi apresentada como religiosa. Até aquele momento Dandinha e eu apenas nos referíamos a ela como "faxineira", ou seja, por seu ofício.

A apresentação foi rápida e terminou por me exaltar. Como ogan, sou tratado com algumas deferências no Candomblé, como aquela de ser visto como um protetor dos terreiros e ser tratado por vodunsis como "pai", um candomblecista a quem todas devem pedir bênçãos. De minha parte, não tinha certeza sobre a filiação candomblecista e tampouco a idade de santo de mãe Sinhá, e respondi à saudação religiosa automaticamente, dando-lhe a benção sem maiores cuidados. Em seguida, subimos o elevador para o apartamento, sem muito conversar.

Ao chegarmos à casa e iniciarmos a faxina, questionei mãe Sinhá sobre sua 
história e se devia lhe chamar de mãe (no sentido de mãe de santo e/ou de vodunsi muito antiga, possivelmente com filhas/os iniciados no Candomblé, ainda que não seja a responsável por uma comunidade de terreiro) ou apenas de Sinhá. Ela me respondeu ser baiana de Salvador, ter àquele momento 60 anos de idade e 46 anos de santo, e que ficava por minha preferência chamar-lhe de mãe ou não. Havia se mudado para Brasília poucas semanas antes, deixando em Salvador seu marido - de quem não depende para nada - e filhos - estes, já adultos e também independentes. Veio para Brasília porque queria mudar de ares e entendeu que seria uma boa ideia se hospedar no terreiro de sua irmã de santo, a mameto ${ }^{7}$ Danda.

Começou neste ponto o meu constrangimento. Mesmo sendo ogan, aprendi desde sempre que, no Candomblé, “antiguidade é posto”. Mais adiante, mãe Sinhá é mais velha de santo do que sou de idade biológica, possui filhas iniciadas e um cargo alto em seu terreiro e, ainda que não seja a mãe de santo da casa, poderia perfeitamente herdá-la de seu pai de santo em caso de seu falecimento. Efetivamente, mãe Sinhá possui os atributos religiosos e comunitários para pertencer à linha de sucessão e se tornar a mameto da casa. Optei, assim, por chamá-la de mãe, da mesma forma que ela me chamava de pai com similar respeito.

Acrescento aqui que o termo mãe é eivado de sentido no contexto candomblecista. Mães - mesmo sem ter terreiros abertos - são lideranças religiosas, sempre assim reconhecidas por quem lhes chama desta maneira, ainda que eventualmente sejam vodunsis não tão velhas de santo quanto mãe Sinhá. Assumem, ademais, proximidade pessoal com as/os filhas/os. Dão-lhes, além de bênçãos, comida, conselhos, cuidados e afeto maternais. Ou seja, não se relacionam com elas/eles de maneira ascética ou burocrática, como por vezes pode sugerir o termo sacerdotisa, mais bem aplicado ao universo religioso cristão - conforme sustentou a makota Valdina em palestra proferida no terreiro de Candomblé Kupapa Unsaba, do Rio de Janeiro/RJ, por ocasião do aniversário de 70 anos de santo de sua líder, a mãe de santo Mabeji ${ }^{8}$.

O fato de Sinhá ser uma mãe candomblecista certamente não a impede de fazer faxina. Pelo contrário, com 46 anos de iniciada ela não apenas trabalhou em várias faxinas em seu terreiro, quanto ainda auxilia/coordena outras tantas. E, como mulher

\footnotetext{
${ }^{7}$ No Candomblé Angola a palavra mameto designa mãe de santo.

${ }^{8}$ Faço aqui referência a um argumento oral, mas saliento que a oralidade - e não a escrita - é estruturante em comunidades de terreiro. Ademais, a palestrante makota Valdina é nacionalmente reconhecida como grande liderança no movimento social afrorreligioso e negro, tendo sido por isso convidada a palestrar sobre o "povo banto", em 20 de abril de 2017, no terreiro Kupapa Unsaba na ocasião da celebração pública do aniversário de 70 anos de santo da mãe Mabeji.
} 
negra, pobre, oriunda da periferia de Salvador/BA, ser faxineira foi uma das mais viáveis opções de carreira que teve em sua vida. Não é acidental que tenha optado pela mesma. Além disso, embora marginalizada e tida como subemprego, a faxina não é uma ocupação menos válida do que nenhuma outra, pelo que ser faxineira não é um ofício vergonhoso para mãe Sinhá - e nem para nenhuma outra pessoa. Sendo assim, qual foi a razão de meu constrangimento?

A resposta aqui não é moderna/colonial, mas propriamente candomblecista. Ogans, a não ser por opção pessoal, não fazem e nem ajudam nas faxinas em terreiros de Candomblé - ou pelo menos não tradicionalmente. E mães velhas de santo tampouco se ocupam demasiadamente com as mesmas. Estas senhoras alcançaram, por sua idade de santo, um lugar de autoridade em que seu papel religioso e comunitário é muito mais o de orientar as gerações mais novas, distribuir bênçãos, realizar atividades religiosas complexas e comandar o funcionamento de seus templos, do que propriamente limpálos, ou executar qualquer outra tarefa passível de cumprimento pelas gerações mais novas de santo. E, ao dizer isto, não postulo que a faxina seja menos importante que a liderança da casa ou que a iniciação de filhas/os de santo. Pelo contrário, busco indicar que a faxina, o cozinhar para as/os mais velhas/os (de idade ou santo), a lavagem de pratos e/ou de banheiros são passos para a senioridade de santo. São etapas cumpridas por todas as vodunsis em seu caminhar para se tornarem mametos ou para, como mãe Sinhá, merecerem similar respeito, como mães candomblecistas a quem todos inclusive ogans - devemos pedir bênçãos.

A casa da qual me mudava, esclareço, não era um terreiro e, como tal, não era vista por mãe Sinhá como um local em que sua senioridade candomblecista importasse, ou mesmo minha condição de ogan. Tratava-se de uma casa que necessitava de serviços profissionais de faxina e cujo dono havia contratado a profissional Sinhá como faxineira. O ponto de inflexão, portanto, não era a casa ser limpa ou não, mas minha relação com aquela mãe candomblecista. Nós não deixamos de ser afrorreligiosos e de respeitarmo-nos mutuamente por estarmos fora de um terreiro. Nosso vínculo "de santo" permanecia existente e, com ele, suas ritualísticas deferências e sociais solidariedades, além de nossas visões de mundo que trazem um sentido de irmandade e destino no encontro de candomblecistas e dos inquices que lhes acompanham. Transformava a relação em algo muito maior e mais significativo do que um contrato de trabalho burguês, mediado e (mal) significado pela moeda e sua troca comercial e financeira. Mãe Sinhá, cabe dizer, é vodunsi filha do inquice da prosperidade e, também 
pela idade de sua divindade ${ }^{9}$, sua visita à minha casa - sobretudo em um contexto de mudança - é percebida como bom presságio em minha cosmopercepção de ogan.

Constrangia-me, portanto, que mãe Sinhá estivesse faxinando minha casa, não porque não devesse, como trabalhadora, ter a faxina como ofício. Mas porque, como tão distinta mãe candomblecista, mesmo embora minha casa não seja um terreiro, não deveria mais fazer faxinas. Sua presença em minha casa significava para mim a visita de uma senhora de grande autoridade e presença espiritual. Gostaria, assim, de ter faxinado minha casa para recebê-la, e não de tê-la fazendo este trabalho para mim.

A lógica moderna/colonial, com sua desequilibrada e desigual economia de mercado, classifica pessoas a partir de sua raça e gênero, reservando os ofícios mais pesados e desgastantes, menos glamourosos e mais mal pagos a pessoas na base da hierarquia. Não há aprendizado comunitário ou esforço coletivo - como em comunidades candomblecistas - para se alcançar um bem comum. Com efeito, a ideia de bem comum possui pouco ou nenhum significado. Há, por outro lado, privilégios, abusos e violências, que tendem a manter e reproduzir o sistema ao longo do tempo (QUIJANO, 2005; SEGATO, 2007).

Mulheres candomblecistas, mormente negras e pobres, por regra tendem a receber nessa colonial modernidade os piores trabalhos, os mais subalternizados disponíveis. Igualmente, vivem suas vidas em periferias urbanas, distantes economicamente - e muitas vezes em quilômetros também - da variedade de bens físicos e serviços (privados e públicos) que os centros privilegiados oferecem. A hierarquização social lhes reserva as piores condições de vida, em todos os sentidos economicamente mensuráveis (HITA, 2014).

Essas mulheres não sofrem esta sistemática marginalização, contudo, em suas comunidades de terreiro. Erigidos da violência da escravidão brasileira, da experiência sui generis dos Calundus coloniais, Candomblés operam sob a lógica da idade de santo. A hierarquização não é aqui construída por privilégios ou violências, mas por um caminho iniciático, que todos devem passar, que envolve compromisso e dedicação às

\footnotetext{
${ }^{9}$ A iniciação de um/a candomblecista implica no que é entendido como o nascimento de seu inquice ritual/momento em que este se vincula mais proximamente à pessoa iniciada. Assim, contar os anos de santo de uma pessoa (salvo raras e casuísticas exceções) é também contar os anos de idade do inquice que a acompanha.
} 
comunidades de terreiro, às mães que lhes formam e que, com os anos, com a senioridade, trazem autoridade.

Há ainda mais do que isso. O Candomblé envolve respeito ritualístico e deferência às lideranças, mas envolve também contato humano. Comunidades de terreiro são, portanto, ricas em imagens visuais, bênçãos e cargos de autoridade, mas também em cheiros, toques, abraços, ritmos, sons, etc. É preciso estarmos integrados a tal modo de vida para internalizarmos a reverência que uma mãe inspira. Estas mulheres foram, finalmente, criadas comunitariamente neste pluriverso tão vivo e nada ascético, e é do âmago do mesmo que emanam suas senioridades. São feitas de idade e experiência, o que necessariamente acumula sempre mais $n g u n z o^{10}$.

Do dia da faxina, um outro exemplo ilustra bem esse processo de construção de autoridade/senioridade: ao final do dia e dos trabalhos, chegou em minha casa a mameto Danda, para buscar sua irmã de santo mãe Sinhá. Neste momento, parei de trabalhar com esta na faxina, pois estava sentada em meu sofá uma autoridade religiosa que, mesmo sem demandar, merecia a exclusividade de minha atenção. Não é o caminho de todas as vodunsis, como conclusão de seu percurso iniciático, tornarem-se mães de santo. Mas aquelas que se tornam, recebem tratamento régio. Com efeito, são rainhas para suas comunidades.

Ogans, cabe dizer, também devem passar por um processo iniciático e também adquirem mais autoridade conforme mais velhos de santo. $\mathrm{O}$ fato de serem merecedores de pedidos de bênçãos de vodunsis e de tradicionalmente não serem responsabilizados pelas faxinas e outros serviços domésticos não implica que não possuam seu próprio caminhar para e pela senioridade, junto a outros ogans e demais religiosos da comunidade. Com efeito, o que difere o caminho do ogan e o da vodunsi são os papeis sociais e ritualísticos esperados de cada um, construídos sobre a longeva e complexa lógica religiosa afro-brasileira. Neste sentido, inclusive, makota Valdina indicou, em conversa logo após a mesma palestra supracitada, que ogans - que já nascem pais devem buscar experienciar um período de filhos (muzenza, na linguagem angoleira), em que efetivamente acumularão as vivências necessárias para se tornarem os pais que nasceram para ser. Cargo é, assim, uma vez mais, deferência e vivência acumulada. Essas andam necessariamente juntas.

\footnotetext{
${ }^{10}$ A palavra ngunzo significa, grosso modo (não existe tradução literal ou abrangente ao português), energia existencial. Aproxima-se do mana dos polinésios, ou do prana dos hindus. É mais amplamente conhecida no Brasil por sua tradução ao iorubá, aportuguesada via música baiana e pelos ritos afrobrasileiros, sobretudo da umbanda: axé.
} 


\section{Reflexões finais}

Busquei com este artigo mostrar que a autoridade de uma mulher (sexo biológico) candomblecista é construída a partir de uma lógica vivencial, em que posições hierarquicamente mais elevadas dentro da religião são alcançadas a partir de seu tempo de iniciação e da partilha de papeis comunitários e ritualísticos variados. Essa história de "vida no santo" (vida no Candomblé) lhes proporciona, além disso, acumulo de ngunzo, conceito de difícil tradução linguística, mas sentido por todos os religiosos.

Busquei deixar explícito ao longo do texto que, na lógica da colonial modernidade, valores êmicos candomblecistas, que dão a essas mulheres notoriedade perante o grupo, não dizem nada. Pelo contrário, a classificação de pessoas iniciada com a colonização do Brasil legou às/aos africanas/os para cá forçosamente trazidas/os, como escravas/os, via tráfico negreiro, os piores trabalhos existentes. Os mais penosos fisicamente e mais desvalorizados. Seus descendentes hodiernos - as/os negras/os brasileiras/os - ainda sofrem com a mesma sina, mesmo que (geralmente) remuneradas/os. Não obstante, o Brasil - as Américas como um todo - tenha sido construído sob sangue escravo negro e indígena, o violento sistema de exploração e subordinação de pessoas baseado em sua cor de pele e origem geográfica nunca foi alterado. Não postulo que deveria tê-lo sido a partir da lógica afrorreligiosa, mas esta claramente - e isto busquei mostrar - é mais justa, inclusiva e abrangente.

Mães candomblecistas, devo dizer, diferentemente de mãe Sinhá, não carecem de ser negras. Embora o componente da cor da pele esteja incluído em minha argumentação, a religiosidade e mesmo a senioridade candomblecista não se estabelecem a partir da cor de pele. Estabelecem-se, sim, por inquice na cabeça, que todos temos - por crença, todas e todos nascem com um inquice que lhes acompanha ao longo de suas vidas e vive, fisicamente, em suas cabeças. É por isso que pessoas brancas também podem ser iniciadas e mesmo se tornarem mametos - ou tatetos, no caso de serem homens. O Candomblé, não obstante, é negro em sua essência - os inquices, orixás e voduns são antropomorfizados como deusas/es negras/os e/ou forças da natureza que se remetem a uma paisagem africana - assim como é feminino, e o lugar de uma mãe candomblecista será sempre racializado como negro, assim como sua indumentária de baiana, seus fios de conta, seus gestos, sua linguagem religiosa, etc. $\mathrm{O}$ racismo religioso, portanto, também enegrece pessoas e opera estruturalmente na lógica 
da colonial modernidade.

Mãe Sinhá, por sua vez, intersecciona diversas características consideradas subalternas no Brasil: mulher, negra, pobre, faxineira, separada e macumbeira. Talvez outras mais existam que desconheço. É, portanto, uma grande autoridade candomblecista, ao mesmo tempo em que está longe de possuir algum poder moderno/colonial. Há um choque de realidades aqui, portanto, que ela articula em sua vida. E, posto que a colonial modernidade é hegemônica, é possível afirmar que o Candomblé - religiões afro-brasileiras como um todo - é subversivo, afirmação esta já feita anteriormente, dentre outras, por Segato (1986/2005) e Birman (1995).

A harmoniosa lógica subversiva de construção de autoridades candomblecista não deve, por outro lado, ser entendida como um processo livre de conflitos. Pelo contrário, não é raro percebermos brigas de egos e desentendimentos graves entre religiosas/os - filhas/os de uma mesma mãe de santo ou ainda biológica - de uma dada comunidade de terreiro, o que algumas vezes leva a rupturas em uma família de santo, que se divide e funda novos terreiros. A discórdia, com efeito, foi o que levou as descendentes religiosas da dinastia nagô Arô a se dividirem entre dois terreiros calunduzeiros oitocentistas soteropolitanos, que são hoje considerados os terreiros de Candomblé mais antigos do país: a Casa Branca e o Alaketu, ambos da nação Ketu. Por outro lado, discórdias pessoais não impedem candomblecistas de reconhecerem a senioridade de uma mãe candomblecista. Ainda que seus mandos ou os caminhos a que lidera possam não ser queridos, sua autoridade - e com ela o inquice que habita em sua cabeça - jamais será questionada. Uma mãe - mameto ou não - será sempre uma autoridade no Candomblé e sempre será respeitada - mesmo que criticada - como tal.

Valores de respeito à vivência, à experiência de vida, das pessoas mais velhas podem ser absorvidos do modo de vida candomblecista por outros grupos sociais. Com ou sem discórdias, as comunidades de terreiro vêm resistindo ao racismo religioso que sofrem desde que os primeiros africanos organizaram Calundus no Brasil. E todas as suas mães, com maior ou menor sofrimento em suas vidas pessoais, vêm liderando esta resistência. Sua empresa pode ser difícil, mas é incrivelmente vitoriosa. E isso é dizer muito na violenta colonial modernidade brasileira. 


\section{Referências bibliográficas}

BIRMAN, Patrícia. Fazer estilo criando gêneros: possessão e diferenças de gênero em terreiros de Umbanda e Candomblé no Rio de Janeiro. Rio de Janeiro: Ed. UERG, 1995.

BOTELHO, Denise; NASCIMENTO, Wanderson. "Educação e religiosidades afrobrasileiras: a experiência dos Candomblés". Participação: a revista do decanato de extensão da Universidade de Brasília, vol. 17, 2010, pp. 74-82.

CARNEIRO, Edson. Candomblés da Bahia. Rio de Janeiro: Ed. Tecnoprint Gráfica, 1961.

HITA, Maria Gabriela. A casa das mulheres n'outro terreiro: famílias matriarcais em Salvador-BA. Salvador: Ed. UFBA, 2014.

LANDES, Ruth. The city of women. Albuquerque: $1^{\text {st }}$ University of New Mexico Press, 1994. Republicação do original de 1947.

NOGUEIRA, Guilherme. "Mães do axé e da resistência: o papel de liderança das mães de santo nas comunidades de terreiro." In: Anais do $2^{\circ}$ Simpósio Internacional de História das Religiões - XV Simpósio Nacional de História das Religiões. Florianópolis: UFSC, 2016. Disponível em: http://www.simposio.abhr.org.br/resources/ anais/6/1461881328_ARQUIVO_artigo_UFSC_vfinal.pdf.

QUIJANO, Aníbal. "Colonialidade do poder, eurocentrismo e América Latina”. In: LANDER, E. A colonialidade do saber: eurocentrismo e ciências sociais. Perspectivas latino-americanas. Buenos Aires: CLACSO, 2005, Colección Sur Sur, set., pp. 227278.

SANTOS, Edmar. O Poder dos Candomblés: perseguição e resistência no Recôncavo da Bahia. Salvador: EDUFBA, 2009. Livro digital em formato Amazon Kindle. 
SCHUMAHER, Shuma, BRAZIL, Érico Vital. Mulheres negras do Brasil. Edição condensada. Rio de Janeiro, SENAC Nacional, 2013.

SEGATO, Rita Laura. La Nación y sus Otros: Raza, etnicidad y diversidad religiosa en tiempos de Políticas de la Identidad.Buenos Aires: Prometeo Libros, 2007.

SEGATO, Rita Laura. Santos e Daimones. Brasília: Editora UnB, 2005.

SILVA, S. "Mulheres de Axé: Matrizes de afetividade e empoderamento constantes." In: REZENDE, M. (org.) Mulheres de Axé. Salvador: Ed. Kawo-Kabiyesile, 2013.

SILVEIRA, Renato. O Candomblé da Barroquinha: processo de constituição do primeiro terreiro baiano de Keto. Salvador: Edições Maianga, 2006. 